\title{
NUEVOS DOCUMENTOS RELATIVOS A LA OBRA DE LOS CENOTAFIOS REALES DE LA BASÍLICA DEL MONASTERIO DE EL ESCORIAL *
}

\author{
José Luis Cano de Gardoqui García \\ (Universidad de Valladolid)
}

\section{RESUMEN}

Con la ejecución, a cargo de Pompeo Leoni y de sus ayudantes, de la obra de los cenotafios o entierros reales de la basílica del Monasterio de El Escorial - diez figuras de bronce - dispuestas en dos grupos a ambos lados del presbiterio, realizada entre 1592 y 1600-, culmina la ambiciosa empresa decorativa de la iglesia principal del Monasterio. Aportamos aquí nuevos documentos, en forma de correspondencia, relativos al grupo funerario de Felipe II.

PALABRAS CLAVE: Pompeo Leoni, Felipe II, Entierros del Monasterio de El Escorial, Duque de Lerma, Felipe III

\section{NEW DOCUMENTS RELATING TO THE WORK OF THE REAL CENOTAFIES OF THE BASILICA OF THE MONASTERY OF EL ESCORIAL}

\begin{abstract}
With the execution, by Pompeo Leoni and his assistants, of the work of the cenotaphs or royal burials of the basilica of the Monastery of El Escorial - ten figures of bronze arranged in two groups on both sides of the presbytery - made between 1592 and 1600, culminates the ambitious decorative enterprise of the main church of the Monastery. We bring here new documents, in the form of correspondence, relating to the funerary group of Felipe II.
\end{abstract}

KEY WORDS: Pompeo Leoni, Felipe II, Burials of the Monastery of El Escorial, Duke of Lerma, Felipe III 
En la primavera de 1592, el escultor italiano Pompeo Leoni, al servicio de la Corte española desde 35 años atrás, iniciaba los trabajos de los grupos funerarios en bronce -los cenotafios del emperador Carlos V y de su hijo, el rey Felipe II-, situados a ambos lados del presbiterio de la Basílica del Monasterio de San Lorenzo el Real de El Escorial ${ }^{1}$.

La obra en bronce de los Entierros, que culminó con la instalación definitiva de las figuras del grupo de Felipe II, en octubre de $1600^{2}$, constituye el último capítulo de una magna obra artística que tuvo su comienzo en enero de 1579 cuando tres artífices italianos: el escultor y lapidario Jácome de Trezzo, Pompeo Leoni y Juan Bautista Comane, maestro de cantería y marmolista, se obligaron, con Juan de Herrera como testigo, a labrar y asentar «así la escultura como la arquitectura y gradas y solado del retablo y depósitos de los cuerpos reales que por mandado y orden de su magd. han de hazer para la yglesia principal del dho monesterio [El Escorial] a tassacions $\rangle^{3}$.

Los tres artistas tomaron la Obra bajo el sistema de Compañia o asociación de sus obradores respectivos para la ejecución de esta empresa cuya envergadura económica y técnica conllevaba un gasto y riesgo evidentes, solo paliados mediante un fondo económico común de 20.000 ducados, en principio para materiales y primeros gastos. Sin embargo, la imposibilidad de un pago conjunto, toda vez que la parte de la obra en bronce se haría fuera de España, en el taller milanés de los Leoni, obligó el 23 de mayo de 1580 a un nuevo contrato por el que se establecía una estricta división de las tareas: Trezzo se encargaría de la Custodia «por la parte de

\footnotetext{
*Quiere ser este trabajo un pequeño pero muy sentido homenaje a mi amigo y compañero Profesor Agustín Bustamante García, quien tantas horas de estudio dedicó a su tan querido Monasterio de El Escorial, y a quién tuve la fortuna de conocerle y aprender tanto de él.

${ }^{1}$ Bien es cierto que las ideas barajadas para la realización de los cenotafios adornados con los grupos escultóricos se remontan a bastantes años atrás. Pero la idea de realizar las figuras en bronce, constituidas en dos grupos de cinco esculturas cada uno -en principio, iban a ser siete-, así como el cambio de material -de mármoles polícromos a bronce fundido y dorado con piedras duras-, parecen ser cuestiones resueltas entre 1591 y 1592. Véanse los estudios bien documentados y precisos de Rosemarie Mulcahy, A la mayor gloria de Dios y el Rey: La decoración de la Real Basílica del Monasterio de El Escorial (Madrid: Patrimonio Nacional, 1992), 191-212. Agustín Bustamante García, "Las estatuas de bronce del Escorial. Datos para su historia (IV)", Anuario del Departamento de Historia y Teoría del Arte 9 10 (1997-1998): 153-158. Agustín Bustamante García, "El grupo sepulcral de Felipe II", en Leone \& Pompeo Leoni, ed. Stephan F. Schröder (Madrid: Museo Nacional del Prado, 2012), 149-159. Almudena Pérez de Tudela, "El cenotafio de Carlos V en la basílica del Escorial", en Leone \& Pompeo Leoni, ed. Stephan F. Schröder (Madrid: Museo Nacional del Prado, 2012), 132-148. Almudena Pérez de Tudela, "Marmi e pietre dure nella decozazione della basilica dell'Escorial sotto Filippo II", en Splendor Marmoris. I colori del marmo tra Roma e L'Europa, da Paolo III a Napoleone III, ed. Grégoire Extermann y Ariana Varela Braga (Roma: De Luca Editori, 2016), 139-158. Todos estos trabajos recogen en buena medida la abundante bibliografía anterior existente sobre los Entierros y, en general, una exhaustiva documentación acerca de la decoración escultórica de la Basílica de El Escorial.

${ }^{2}$ Mulcahy, A la mayor gloria, 210.

3 Agustín Bustamante García, "Las estatuas de bronce del Escorial. Datos para su historia (I)", Anuario del Departamento de Historia y Teoría del Arte 5 (1993): 50, nota 39.
} 
afuera de xaspe fino oriental y todo lo demás tocante a los dichos jaspes»; Pompeo de los elementos y figuras de metal -las molduras y doce Apóstoles de la Custodia, las quince esculturas del Retablo, y «todas las basas y capiteles y molduras y otras cosas que han de ser de bronzes tocantes a dicho retablo»-. Finalmente, Comane «de todo lo necesario para el dicho retablo, ansí de jaspes como de mármol y otras qualesquier suertes de jaspes embutidos y de qualquier suerte de piedras». Por otra parte, la Compañia se ampliaba con la participación de León Leoni, padre de Pompeo, en una dieciseisava parte y, en un porcentaje similar, con la de Juan Antonio Maroja, oficial de Trezzo especializado en la extracción de mármoles y jaspes en las canteras españolas. Tras la muerte de Comane, en julio de 1582, Trezzo asumirá toda la dirección de la Obra ejecutada en España ${ }^{4}$.

Esta parte de la Obra concluyó en septiembre de 1590 con la colocación de todas las figuras del Retablo Mayor de la basílica escurialense ${ }^{5}$ Habían transcurrido, pues, 11 años desde la formación de la Compañia. Aún faltaban 10 años y 10 meses más para la terminación de los bultos sepulcrales. Como indica el propio Bustamante, en 1600 «se concluía así, tras veintiún años y diez meses de trabajo, la gran empresa escultórica del retablo mayor y los grupos de los entierros. Se había tardado en ello lo mismo que en hacer la arquitectura del Monasterio» ${ }^{6}$.

Ello no quiere decir que, en paralelo a la finalización de las esculturas del Retablo, se llevaran a cabo importantes tareas en el diseño y elaboración de los grandes escudos reales, de bronce dorado y mármoles y jaspes polícromos, que irían situados sobre cada grupo funerario. Estos trabajos concitaron, a partir de 1586 y hasta 1592, la presencia de destacados artistas con Jácome de Trezzo a la cabeza, algunos de ellos partícipes más tarde, como se dirá, en la elaboración de los Entierros, a excepción de Trezzo, fallecido el 23 de septiembre de 1589. Así, Juan Pablo Cambiago y Francesco del Gasto; el dorador Martín Pardo; pero también otros artífices: Julio y Jerónimo Miseroni, Clemente Virago, Antonio Fasol y el propio Pompeo Leoni?.

\footnotetext{
${ }^{4}$ Jean Babelon, Jacopo da Trezzo et la construction de l'Escurial. Essai sur les arts à la cour de Philippe II, 1519-1589 (Bordeaux-Paris: Feret, 1922), 294-297, doc. 23. Archivo General de Simancas (AGS), sec. Casa y Sitios Reales, leg. 261, fol. 131. Citado por José Luis Cano de Gardoqui García, "Datos para la escultura cortesana del último tercio del siglo XVI. Aspectos socio-económicos", Boletín del Seminario de Estudios de Arte y Arqueología 56 (1990): 471, nota 4. Respecto a Comane, véase José Luis Cano de Gardoqui García, "COMANE, Juan Bautista”, en Allgemeines Künstlerlexikon (München-Leipzig: K.G. Saur, 1998), vol. 20, 423.

5 Bustamante, "Las estatuas de bronce (IV)", 153.

${ }^{6}$ Ibídem, 161.

7 Acerca de los escudos reales, véase Pérez de Tudela, "Marmi", 144-146. En marzo de 1590, Pompeo realizó el león para el castillo del escudo de Felipe II, Bustamante, "Las estatuas (IV)", 153154 y 163 , nota 20.
} 


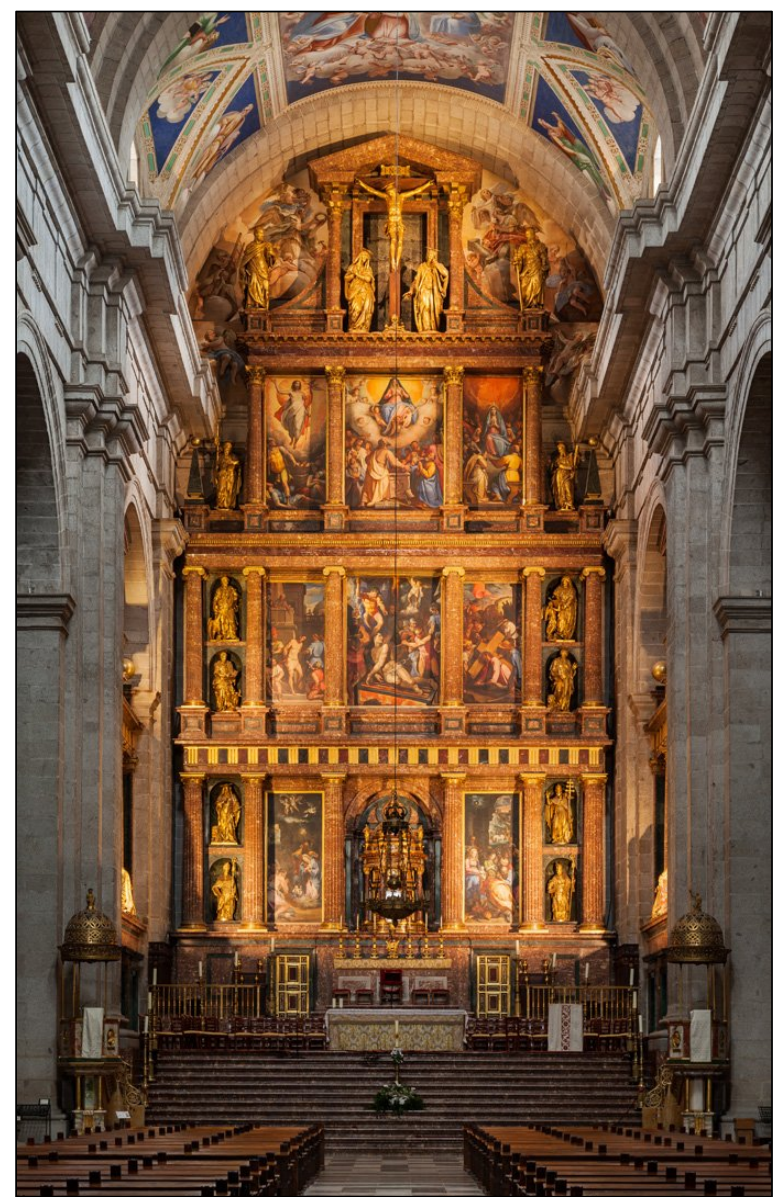

Fig 1. Retablo Mayor de la Basílica del Real Monasterio de El Escorial.

El abundante material documental referido a estas obras contrasta con la ausencia del contrato original suscrito entre Felipe II y Pompeo para la realización de los Entierros. Mulcahy cree que puede datar de fines de marzo de 1590, una vez terminada la obra escultórica del Retablo ${ }^{8}$. Por su parte, Bustamante piensa que no llegaría a establecerse contrato alguno, «sino nuevas disposiciones y normas al contrato [la Compañía de Trezzo, Leoni y Comane] de 1579, algo muy característico de Felipe II, y usado continuamente durante la edificación y ornato de San Lorenzo el Real " ${ }^{9}$. Mientras, Pérez de Tudela prueba documentalmente que ya en 1592 Pompeo Leoni se hallaba trabajando en el proyecto ${ }^{10}$. En efecto, ese año el maestro de cantería y escultor italiano Baltasar Mariano, ayudante de Pompeo Leoni en su taller milanés al menos desde 1584 en la obra de bronce de las esculturas del

\footnotetext{
${ }^{8}$ Mulcahy, A la mayor gloria, 204.

${ }^{9}$ Bustamante, "Las estatuas (IV)", 156.

10 Pérez de Tudela, "El cenotafio", 136, nota 40.
} 
Retablo ${ }^{11}$ recibía un pago de 798 reales correspondiente a los meses de abril a agosto de 1592 a cuenta de su salario de 16 ducados al mes contabilizado «desde nueue de abril del año pasado de 1592 que començo a trauajar en la dhas figuras de los entierros» ${ }^{12}$.

Para mayor precisión, una cédula real fechada el 1 de junio de 1593 que determina para Leoni un pago mensual de 50 ducados del dinero consignado para la fábrica de El Escorial y retroactivo al 1 de abril de 1592, por todos los días de su vida, aún después de terminada la obra de los Entierros ${ }^{13}$, indica que el escultor ya había comenzado por entonces dicha obra, lo que hace pensar a Mulcahy como la fecha más probable para el contrato de los bultos funerarios ${ }^{14}$.

Sea como fuere, es Pompeo Leoni quien iba a asumir ahora en solitario la obra de los Entierros, frente a la antigua empresa del Retablo y Custodia, una vez fallecidos sus compañeros Comane y Trezzo, éste apenas poco después de la vuelta a España de Pompeo desde Milán, en septiembre de 1589.

Como único responsable de lo que quedaba por hacer -los Entierros-, y una vez decidido por Felipe II que esta obra habría de ser ejecutada en Madrid para así el monarca poder seguir de cerca su desarrollo, el antiguo taller de Jácome de Trezzo, sito en la parroquia madrileña de San Martín, se convertirá, una vez adquirido por el rey, en el obrador de Pompeo ${ }^{15}$.

Esta circunstancia de la acomodación de la casa madrileña de Trezzo como taller de Pompeo es importante por diversas razones.

Si en la obra del Retablo y Custodia Pompeo había actuado desde el punto de vista organizativo y administrativo, como un maestro de obra, al gestionar el recibo y distribución de la provisión dineraria aplicada a la empresa, con la contrata y pago de

11 José Luis Cano de Gardoqui García, "El taller de Pompeo Leoni en Milán y la obra de bronce para el retablo mayor y la custodia del Monasterio de El Escorial. Nuevos datos para su estudio", en El modelo italiano en las artes plásticas de la Peninsula Ibérica durante el Renacimiento, coord. María José Redondo Cantera (Valladolid: Universidad de Valladolid, 2004), 462.

12 Bustamante, "Las estatuas (IV)", 165, nota 33.

13 Mulcahy, A la mayor gloria, 205 (Un traslado de esta cédula en AGS, sec. Contaduría Mayor de Cuentas (CMC), $2^{a}$ época, leg. 970, s. p.: «y para después de acabada la dicha obra [...], le he mandado consignar la paga de los dichos cincuenta ducados al mes en el nuestro Receptor General de Penas de Cámara»).

14 Véase también Bustamante, "Las estatuas (IV)", 156.

15 Pérez de Tudela, “Marmi”, 146: «L'opera intera venne realizzata nella casa madrilena di Jacopo da Trezzo, comprata da Filippo II nel febbraio del 1589 e accresciuta a poco a poco con l'acquisto di abitazioni circostanti». Eugène Plon, Les mâitres italiens au service de la maison d'Autriche. Leone Leoni, sculpteur de Charles V et Pompeo Leoni, sculpteur de Philippe II (Paris: Librairie Plon, 1887), 227. Citado por María José Redondo Cantera, El sepulcro en España en el siglo XVI. Tipología e Iconografía (Madrid: Centro Nacional de Información y Documentación del Patrimonio Histórico, 1987), 73 y por Mulcahy, $A$ la mayor gloria, 205. 
ayudantes y materiales, ahora, con los Entierros, el escultor quedaba liberado de estas responsabilidades, quedando éstas a cargo de Felipe II. Quedaban bastante atenuados, pues, todos aquellos problemas materiales -burocráticos y económicosajenos a una actividad artística que, por el contrario habían lastrado negativamente la obra en bronce para el retablo y custodia realizada en Milán ${ }^{16}$.

En segundo lugar, el establecimiento del obrador de Leoni en el antiguo taller de Jácome de Trezzo permite a Pompeo servirse de los ayudantes del escultor y lapidario fallecido: su sobrino Trezzo el Mozo, Julio Miseroni, Juan Pablo Cambiago, Francesco del Gasto, etc., así como de ciertos artífices españoles, como Antón de Morales, Juan de Arfe o Juan de Ribas. Pero también Pompeo trae de Italia ciertos maestros y oficiales que habían trabajado con él en la obra del retablo, caso del escultor Milán de Vimercado, de los maestros de cantería y escultores Baltasar Mariano y Pietro Bosso -éste también fundidor-, y de los cinceladores Jusepe Uliciano (o Feliciano) y Francesco de la Giexa (o de la Iglesia) ${ }^{17}$.

Finalmente, la realización de los Entierros en Madrid determina que, frente a la abundante documentación existente relativa a la obra del retablo y custodia en su conjunto, o a la de la arquitectura de los cenotafios, respecto a las cuestiones prácticas de estas obras ${ }^{18}$, la fábrica de los Entierros carece en general de correspondencia, siendo la documentación, como indica Mulcahy «de carácter oficial rutinario, y se refiere a pagos, solicitudes y peticiones de material» ${ }^{19}$.

Al respecto, los trabajos de Mulcahy, Bustamante y Pérez de Tudela, ya citados, proporcionan un estudio exhaustivo del proceso seguido en la elaboración y conclusión del grupo de Carlos V, comenzado en 1592 y terminado el 10 de noviembre de 1598, fecha de la colocación de las cinco figuras en su lugar de destino ${ }^{20}$ por lo que no vamos a extendernos en dicho grupo.

${ }^{16}$ Cano de Gardoqui, "El taller de Pompeo", 461. Respecto a la provisión dineraria destina a la hechura de los Entierros, una cédula real de 24 de agosto de 1592 ordenaba al pagador Domingo de Mendiola «que del dinero de la consignación de la fábrica del Escorial entregue al pagador Domingo de Lacorzana [pagador de las obras del Alcázar de Madrid] por libranzas de Juan de Ibarra hasta 500 ducados cada mes para que los gaste en las figuras de bronce que Pompeo Leoni ha de hacer para los entierros que están a los lados del altar mayor». Dos años más tarde, otra cédula real fechada el 24 de agosto de 1594, venía a aumentar esta provisión hasta 1.000 ducados al mes, pues «no se puede suplir la costa que esta obra ba de tenen» (AGS, sec. CMC, $2^{a}$ época, leg. 970, s.p.).

${ }^{17}$ Cano de Gardoqui, "El taller de Pompeo", 462. Véase también José Luis Cano de Gardoqui García, "Noticias sobre el escultor italiano Milán de Vimercado", Boletín del Seminario de Estudios de Arte y Arqueología 54 (1988): 383-392.

18 Mulcahy, A la mayor gloria, 192 y Bustamante, "El grupo sepulcral", 149.

${ }^{19}$ Mulcahy, Ibídem, 192.

${ }^{20}$ Ibídem, 210. El grupo funerario de Carlos V está constituido por las figuras del emperador, de la emperatriz Isabel de Portugal, de la emperatriz María, hija de Carlos V, y de las de María de Hungría y Leonor de Francia, hermanas del emperador. 
Así también, el mismo tipo de documentación y similar dinámica investigadora concurre en el proceso ejecutivo, un tanto oscuro, del grupo de Felipe II. Tanto Mulcahy como Bustamante lo han reconstruido sin «apenas [...] otras noticias que los pagos, es decir, información económica y administrativa» ${ }^{21}$.

De las nuevas relaciones contractuales fijadas con Pompeo para la realización de las figuras del cenotafio de Felipe II, a fines de abril de 1597, se desprende el hecho cierto de la necesidad de terminar cuanto antes los bultos funerarios, si bien teniéndose en cuenta la experiencia adquirida con el grupo de Carlos V.

El grupo del emperador había sido ejecutado, reparado y colocado en un plazo aproximado de seis años. Ahora, el nuevo contrato fijaba tan sólo un tiempo de dieciocho meses, desde el 1 de enero de 1597 hasta fines de junio de $1598^{22}$.

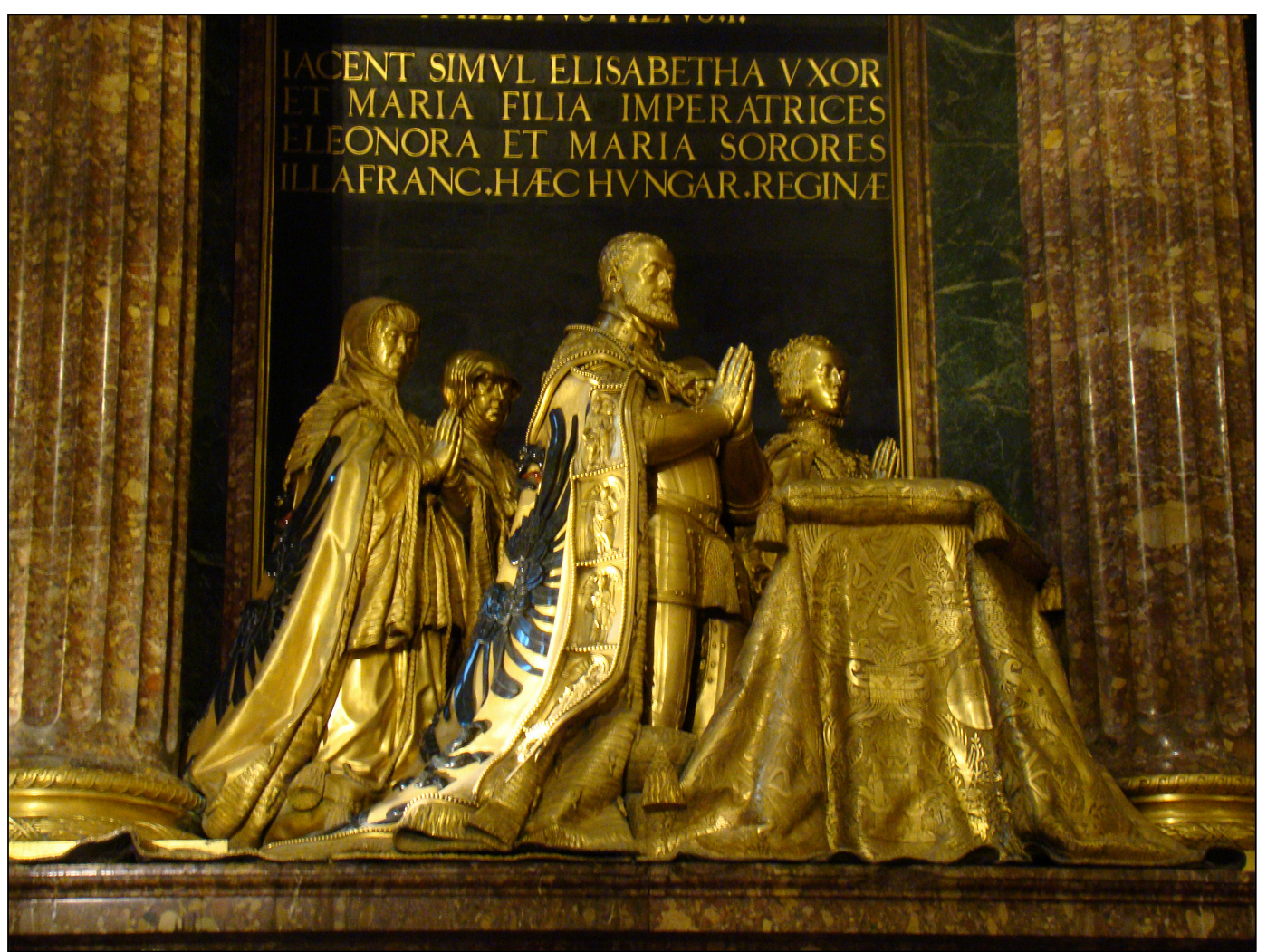

Fig. 2 Pompeo Leoni, grupo escultórico de la Familia de Carlos V, Real Monasterio de El Escorial, Patrimonio Nacional.

${ }^{21}$ Bustamante, "Las estatuas (IV)", 152. El grupo funerario de Felipe II se halla compuesto por las figuras del propio rey, del príncipe don Carlos y de tres de las cuatro esposas del monarca: la princesa María de Portugal y las reinas Isabel de Valois y Ana de Austria.

${ }^{22}$ Ibídem, 150 y Mulcahy, A la mayor gloria, 205. 
La enfermedad del anciano monarca, su propio interés, apremiaban el encargo. Y el plazo de tiempo se cumplió, al menos respecto a la fundición de las figuras, no así en los reparos, dorado y colocación. A pesar de la continuidad en los trabajos del mismo equipo de artífices ayudantes de Pompeo en su taller madrileño, Felipe II, fallecido el 13 de septiembre de 1598, no llegó a supervisar dichas tareas ni ver emplazadas las figuras en su lugar de destino; de ahí que el propio rey «en su codicilo dejara dispuesto que se acabaran los bultos de bronce $»^{23}$.

Los pagos y otras noticias de carácter administrativo relativos a los trabajos seguidos para el cenotafio de Felipe II, así como para su colocación, que tuvo lugar el 22 de octubre de 1600, se hallan bien documentados por Mulcahy, Bustamante y Pérez de Tudela, entre otros autores ${ }^{24}$.

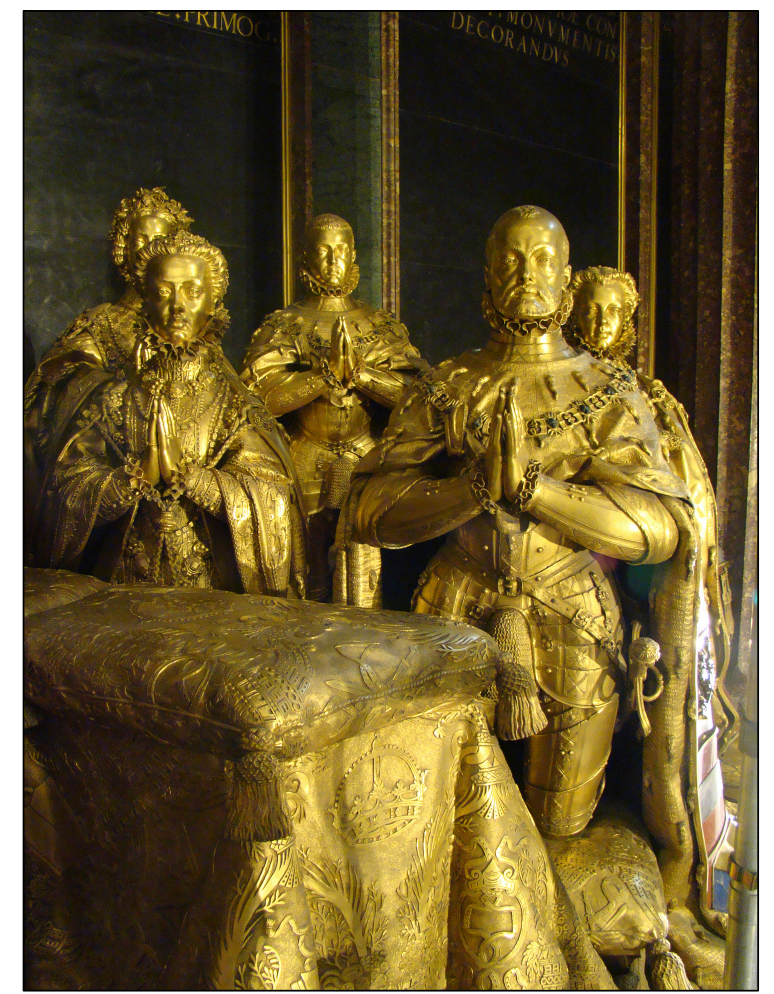

Fig. 3. Pompeo Leoni, grupo escultórico de la Familia de Felipe II, Real Monasterio de El Escorial, Patrimonio Nacional (vista lateral).

${ }^{23}$ Bustamante, "Las estatuas (IV)", 150.

${ }^{24}$ Mulcahy, A la mayor gloria, 210. Bustamante, "Las estatuas (IV)", 159 y Bustamante, "El grupo sepulcral", 150-151. Pérez de Tudela, "El cenotafio", 141. Pérez de Tudela, “Marmi”, 151-152. 


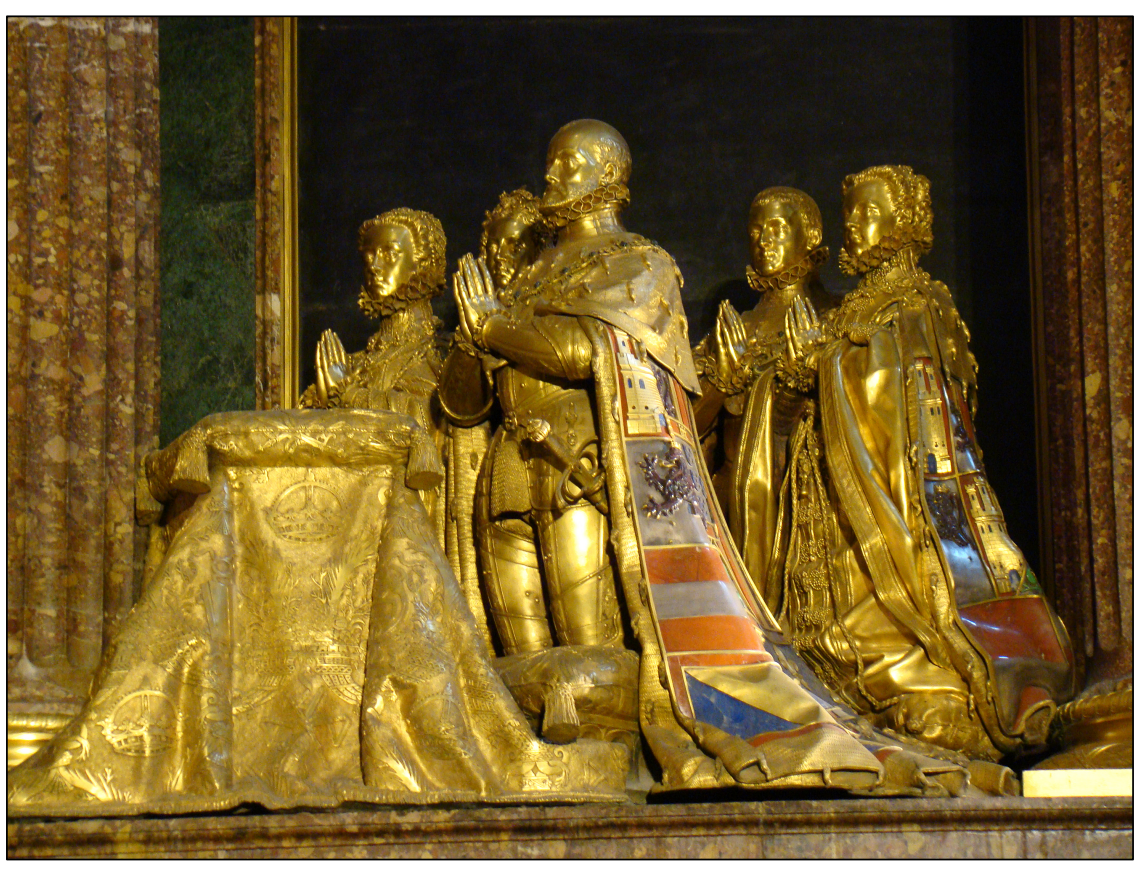

Fig. 4. Pompeo Leoni, grupo escultórico de la Familia de Felipe II, RealMonasterio de El Escorial, Patrimonio Nacional (vista lateral).

Pero la liquidación definitiva de todas las cuentas, como se desprende de toda esta información administrativa, no terminó sino, al menos, hasta 1604. Por ejemplo, y con relación a estos retrasos, en marzo de 1604 se le adeudaba aún a Pompeo Leoni su salario de 50 ducados mensuales correspondiente a los meses de diciembre de 1598 y de enero de $1599^{25}$.

Sin duda, la entronización del nuevo monarca, Felipe III, trajo consigo desde el principio una apariencia de continuidad con relación a la etapa anterior, plena, sin embargo de significativos cambios políticos, administrativos, organizativos y económicos ${ }^{26}$.

Con relación a esta obra de Pompeo Leoni, comenta Bustamante que, tras el fallecimiento de Felipe II «se recortaron los recursos económicos y la organización montada en 1593 para financiar la ejecución de los sepulcros se resintió gravemente. La obra empezó a ralentizarse y a funcionar de modo intermitente, pues no había oro [...]. Afortunadamente, con la decidida intervención de don Juan de Borja, en 1600 se allegaron medios y oro y Martín Pardo acabó de dorar las figuras y el sitial del grupo de Felipe $\mathrm{II}^{27}$.

\footnotetext{
${ }^{25}$ AGS, sec. CMC 1ª época, leg. 1760.5 (Data de salarios del pagador Domingo de Mendiola).

${ }_{26}$ Antonio Feros, El Duque de Lerma. Realeza y privanza en la España de Felipe III (Madrid: Marcial Pons, 2002), 109-135.

${ }^{27}$ Bustamante, "El grupo sepulcral", 150-151.
} 


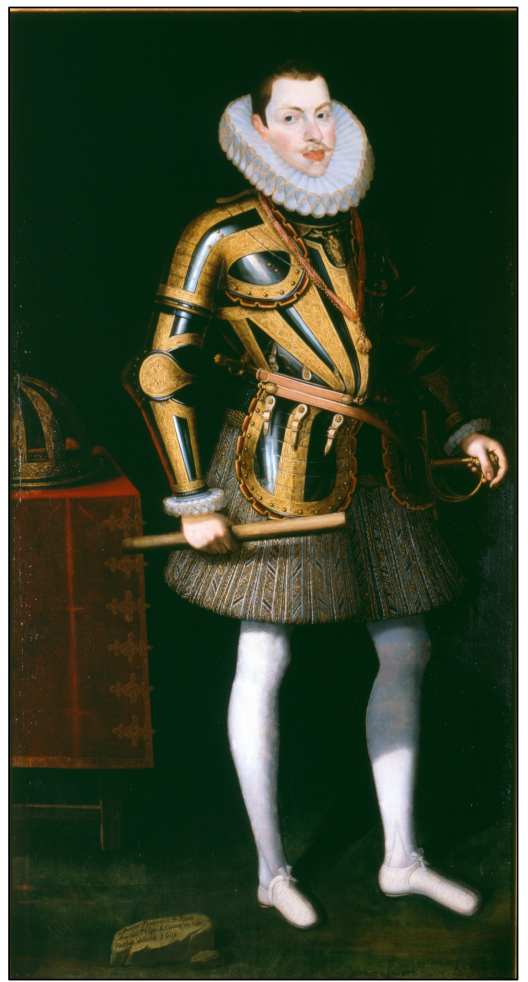

Fig. 5. Juan Pantoja de la Cruz, Felipe III, 1605, Real Biblioteca de El Escorial, Patrimonio Nacional.

Resulta muy interesante la "intervención" de este don Juan de Borja, conde de Mayalde y nuevo Consejero de Estado con Felipe III, sobre todo desde el punto de vista del sesgo que había tomado ya por esta época la nueva Corte. Ahora bien, si la participación del Consejero no fue exactamente como la relatada en 1603 por Fray Jerónimo de Sepúlveda ${ }^{28}$ sí nos revela el nuevo estado político surgido con la llegada

${ }^{28}$ Id. "Las estatuas (IV)", 161 y nota 73. El autor cita un relato extraído de las memorias escritas en 1603 por Fray Jerónimo de Sepúlveda, monje jerónimo de San Lorenzo de El Escorial, a su vez recopiladas por Julián Zarco Cuevas, Documentos para la Historia del Monasterio de San Lorenzo el Real de El Escorial. IV. Historia de varios sucesos y de las cosas notables que han acaecido en España y en otras naciones desde el año de 1584 hasta el de 1603. Escrita por el P. fray Jerónimo de Sepúlveda, el Tuerto, monje jerónimo de San Lorenzo el Real de El Escorial (Madrid: Imprenta Helénica, 1924), 225-226. Transcribimos aquí un fragmento extraído de esta obra de Zarco y citado por Bustamante: «[1600] En estos días envió el Rey a decir a don Juan de Borja, mayordomo mayor de la señora Emperatriz su agüela, que le hiciese placer de mandar que los bustos que estaban en casa del yerno de Jácome de Trezzo, de las personas reales de su padre y madre, con otros tres, que diesen orden como se acabasen y se trujesen a esta su Casa [...] Luego puso por obra don Juan de Borja, como tan buen caballero, lo que le fue mandado por su Rey. Fue en persona en casa de Jácome de Trento (sic) y pidió le enseñasen los bultos de las personas reales y mandó que luego en la hora se acabase, y dijéronle como faltaba plata y oro y que por eso no estaban acabados muchos días había. Él les dijo: “Acudid luego a mi posada que yo os daré todo lo necesario, y os mando no alceis las manos de ello hasta que los acabéis". Fueron los oficiales a 
al trono de Felipe III. Fundamentalmente, el imparable ascenso del V Marqués de Denia, Francisco Gómez de Sandoval y Rojas, desde 1599 Duque de Lerma, ya manifiesto desde los comienzos del nuevo reinado, y su posición de primacía en la casa real, inmediatamente después de la muerte de Felipe II $^{29}$.

Una prueba manifiesta de la privilegiada posición adquirida por Lerma en su papel de intermediario absoluto entre las decisiones, la voluntad, los intereses de Felipe III y el Consejo de Estado, así como en relación a otras Juntas y Consejos de la Monarquía, es la correspondencia cruzada entre el Duque y don Juan de Borja entre 1598 y 1606, año de la muerte de este último, estudiada y, en parte publicada por Feros ${ }^{30}$.

Por lo que aquí nos interesa, entre esta nutrida correspondencia, hemos hallado una serie de cartas, tres en concreto, cuyo tema fundamental queda referido al estado en el que, en noviembre de 1599 y marzo de 1600, se encontraban las tareas de reparo y dorado del grupo funerario de Felipe II llevadas a cabo por Pompeo Leoni y sus ayudantes, lo cual viene a llenar un vacío documental en la historiografía de la obra de los Entierros de El Escorial ${ }^{31}$.

No resulta extraño que don Juan de Borja (1533-1606) actuara en calidad de visitador e informador puntual para Felipe III a través de Lerma de los trabajos llevados a cabo en el taller madrileño de Leoni. Juan de Borja, tío de Francisco Gómez de Sandoval, había adquirido una gran experiencia administrativa durante el reinado de Felipe II. Embajador en Portugal en 1569 y, más tarde, embajador ante el emperador Rodolfo II, Borja volvería a España en 1581 en calidad de mayordomo mayor de la emperatriz María hasta la muerte de la hermana de Felipe II en 1603. A partir de la privanza del duque de Lerma, nombrado consejero de Estado a finales de 1598 y, un año después consejero de Portugal, Juan de Borja «se convirtió en uno de los ministros más próximos y más valiosos para Lerma [...], participando en muchas de las juntas creadas durante los primeros años del reinado» ${ }^{32}$ Asimismo, no conviene olvidar la proximidad del antiguo taller de Jácome de Trezzo respecto al Monasterio

su casa por lo necesario para dorarlas, y el don Juan de Borja iba cada día en casa de Jácome a ver como andaba la obra y daba mucho calor a ella y no la dejó hasta que las acabaron...».

${ }^{29}$ Feros, El Duque de Lerma, 111. Véase también Bernardo José García García, "Los marqueses de Denia en la Corte de Felipe II: Linaje, servicio y virtud", en Felipe II (1527-1598): Europa y la monarquía católica, 2, dir. José Martínez Millán (Madrid: Parteluz, 1998), 305-332.

${ }^{30}$ Feros, El Duque de Lerma, 241 nota 108. Esta correspondencia puede ser consultada en la British Library de Londres, en la sección de Western Manuscripts, con la signatura Additional Manuscript 28422-28425. Las cartas cuentan con una breve descripción catalográfica debida a Pascual de Gayangos y publicada en su magna obra Catalogue of the Manuscripts in the Spanish Language in the Bristish Museum, 3 (London: The Trustees of the British Museum, 1881), 195-233.

${ }^{31}$ Las tres cartas se transcriben en el Apéndice Documental de este trabajo: British Library (BL), Add. Ms. 28422, folios 330-334. Véase Gayangos, Catalogue, 201.

32 Feros, El Duque de Lerma, 241. 
de las Descalzas Reales, residencia de la emperatriz María, pues Borja residía en las inmediaciones con la finalidad de servir de forma más eficaz a su señora.

Estas tres cartas dirigidas por don Juan de Borja al duque de Lerma y los comentarios de este último en sus márgenes, respetando, al menos en el papel, las decisiones de Felipe III, revelan la extraordinaria confianza entre tío y sobrino, manifestada también en el plano político a modo de una alianza firme en la que Borja actúa como intermediario y agente de Lerma hasta su fallecimiento en 1606.

Sin más, publicamos aquí íntegramente los contenidos de dichas cartas. A la hora de facilitar su lectura, hemos optado por la modernización de la ortografía de los textos, actualizando palabras, términos y puntuación. También se ha procurado, con ayuda de la historiografía sobre este tema, contextualizar algunos aspectos para su mejor entendimiento. 


\section{APÉNDICE DOCUMENTAL}

\section{CARTA DE DON JUAN DE BORJA AL DUQUE DE LERMA. MADRID. 16 DE NOVIEMBRE DE $15999^{33}$}

\section{Folio 332:}

\section{DON JUAN DE BORJA}

El estado de las figuras y genealogías reales, cabezas para relicarios y otras obras que se hacen para el Monasterio de San Lorenzo en la casa y obrador que fue de Jácome de Trezzo es el siguiente:

Las figuras del emperador y emperatriz Nuestros Señores y demás personas reales que están a la parte del evangelio están asentadas y puestas.

Faltan por poner las de la parte de la epístola, que son las del rey y reina doña Ana, Nuestros Señores, princesa doña María de Portugal, reina doña Isabel, príncipe don Carlos, las cuales están acabadas, y también el sitial. Faltan solo los rostros y manos de la reina doña Isabel y príncipe don Carlos, que se acabarán en dos meses.

Acabado esto, Pompeo ni sus oficiales no son más necesarios hasta que, después de doradas, se hagan asentar en San Lorenzo.

Los escudos, cogollos y coronas de la descendencia de la parte del emperador están vaciados y reparados, solo falta acoplarlos ${ }^{34}$.

Los de la parte de Su Magd. faltan por reparar los cogollos y algunas coronas. Está gastado en esto más de 5.000 ducados. Acabar sea lo que falta con menos de 2.000 . Y para ello convendría encargarlo por concierto de tiempo y precio a persona que lo haga a vista y satisfacción de las personas diputadas para ver esta obra, y que las acople y asiente en sus lugares después de dorarlas, lo cual se podrá hacer dentro de un año.

33 BL, Add. Ms. 28422, fols. 332, 332v, 333 y 333v.

34 Se había proyectado, realizado pero, finalmente, no colocado o acoplado, un complejo programa heráldico constituido por los árboles genealógicos de la familia real para ser situados en los espacios murales de ambos grupos, entre las columnas, justo debajo de las inscripciones latinas, tal y como puede verse en el dibujo de Jehan Lhermite, ayuda de cámara de Felipe II, ejecutado en 1597. Las genealogías reales seguían realizándose en 1599 y 1600 a base de elementos vegetales y coronas en bronce dorado envolviendo los escudos de piedras duras. Mulcahy, A la mayor gloria, 201-203; Pérez de Tudela, "El cenotafio", 141 y Pérez de Tudela, "Marmi", 152. Al respecto, comentaba en 1601 Fray José de Sigüenza: «se pretende poner en el uno y en el otro [los dos cenotafios, el de Carlos V y el de Felipe II] las armas y blasones de sus padres y antepasados, hechos de los mismos jaspes y piedras, y guarnecido de florones y ramos en bronce dorado, que harán aquello más ilustre, aunque ahora no estén puestos» (Mulcahy, A la mayor gloria, 203). 
De las 64 cabezas que se hacen para los relicarios faltan por hacer solas diez. Están pagadas veintisiete. Acabadas todas, que será en breve, se deberán 37.000 reales ${ }^{35}$.

Del frontal y grada de chapas de cobre de medio relieve, falta por soldar con plata las quebraduras de las chapas y por hacer los tornillos y las molduras, que se hará en breve. Monta esta obra 400 ducados.

Hay oro para dorar las figuras y cabezas, lo cual conviene se haga luego por ser el tiempo a propósito. Y porque, concluido con esto, se ahorraran los salarios que tienen las

\section{Folio 332v:}

personas que entienden en esta obra que son las siguientes:

Pompeo 600 ducados. Jácome de Trezzo 100 ducados. Joan Pablo 200 ducados. Martín Pardo 100 ducados. Francisco del Gasto 100 ducados. Un llaverizo y un portero un ducado cada día. Los cuales salarios tienen consignados por Su Magd. hasta que esta obra se acabe, la cual tienen a tasación; y por esto, y tener posadas de aposento, holgarán que dure el acabarse, y así importa abreviar con ello.

Faltará oro para dorar los escudos, cogollos y coronas, y éste se sacará de la escobilla que quedará del dorado de las figuras y cabezas, que se dorarán entretanto que los cogollos y escudos se acaban, en lo cual habrá harto o faltará poco.

Hay en esta casa gran cantidad de bronce, estaño, cera, madera, grandes piezas de jaspe diferentes, maromas, roldanas, vasos de cobre y latón y cantidad de hierro que, estando las figuras doradas y puestas en San Lorenzo, no será menester. Todo esto vale mucho dinero, lo cual sería bien inventariar y tasar desde luego y vender, reservando lo que fuese necesario hasta asentar las figuras, y de ello pagar lo que se debe a los oficiales que será: a Joan Pablo y Jácome 1.000 ducados; a Milán [de Vimercado] y Baltasar [Mariano] 2.000 ducados; a Martín Pardo 3.000 ducados, que son 6.000 en todo.

Toda esta obra, excepto las cabezas y frontal, está consignada en lo que procede de la marca ${ }^{36}$ Esta renta es de menos valor de lo que se pensó cuando se consultó a Su

${ }^{35}$ Juan de Arfe, platero y escultor de fama por las custodias realizadas para las catedrales de Ávila, Sevilla y Valladolid, había contratado en 1597 la realización de 64 bustos relicarios para el Monasterio de El Escorial, que serán pintados por Fabrizio Castello. Fernando A. Martín, "Relicarios y piezas de altar en la basílica del Monasterio de El Escorial", Reales Sitios 82 (1984): 29-36. Arfe se incorporaría al equipo de Pompeo Leoni en 1598, colaborando más tarde con el escultor italiano en los monumentos funerarios de los Duques de Lerma, situados en el Museo Nacional de Escultura de Valladolid.

${ }^{36}$ Esta renta de la marca y referencia posterior en el documento al Marcador Mayor, parece convenir a las cantidades de dinero que en concepto de multa procederían del uso fraudulento de las marcas impresas en las monedas en circulación, con el fin de garantizar el control fiscal del Estado 
Magd. que, entendiendo los ministros que valdría mil ducados cada mes, no vale 500, porque las condenaciones de penas de cámara de los lugares de señorío que entraban en ella se han adjudicado por el Consejo a los señores de ellos, y así ha bajado mucho esta renta.

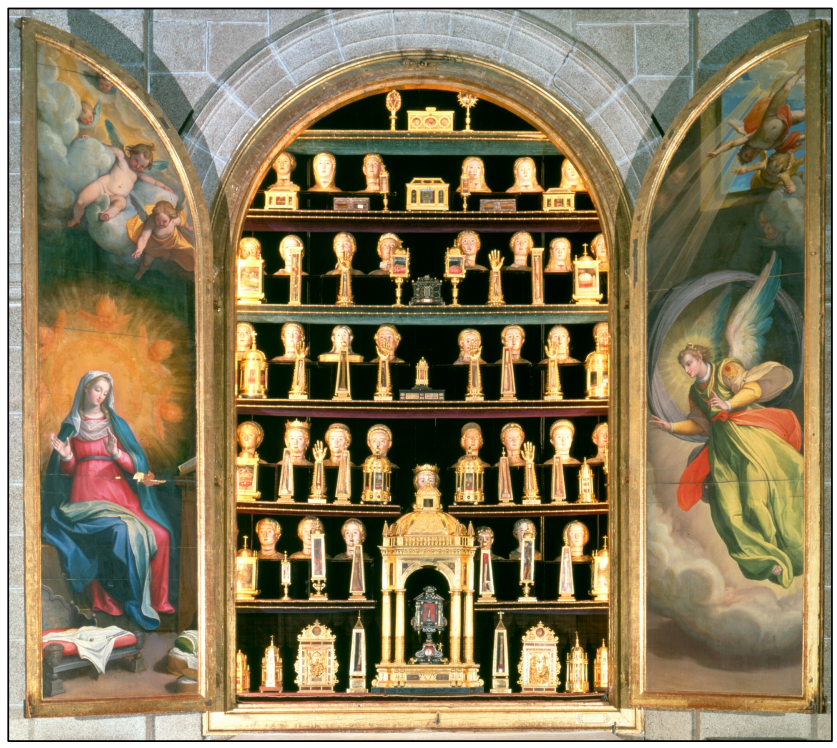

Fig. 6. Federico Zuccari, armario-relicario de La Anunciación con los bustos-relicarios femeninos de Juan de Arfe y Lesmes Fernández del Moral, Real Monasterio de El Escorial, Patrimonio Nacional.

\section{Folio 333:}

Y en lo procedido de ella está señalado al Marcador Mayor 500 ducados al año, el cual tiene cinco oficiales con veinticuatro reales de salario cada día, y no importa la mitad lo que hacen y se podría excusar parte de este gasto, por lo cual ha habido falta de dinero, y si no la hubiera estaría acabada toda esta obra.

Queda después de acabada la casa, que es un suelo cuadrado de 147 pies por lado, con poco huerto, noria, vivienda bastante que, aunque no costó más de 6.500

sobre la legalidad de la ley del metal, valor y peso de las monedas. En este sentido, conviene tener en cuenta que, por una parte, actuaban los ensayadores o marcadores de las diversas Casas de Moneda existentes en la España de la época -Segovia, Valladolid, Cuenca, Toledo, etc.-. Pero, por otra parte, actuaba el Ensayador o Marcador Mayor del Reino quien, como indica Royo Martínez «podría definirse como el responsable máximo estatal en la vigilancia y control de todo lo relativo tanto al peso de los marcos, pesas y granos que se usaban en todo el reino, así como de la calidad de la moneda y de la custodia de los troqueles con los que se acuñaban las pesas y marcos». María del Mar Royo Martínez, "Datos documentales sobre plateros y ensayadores en la Ceca de Cuenca en el siglo XVI", Boletín del Museo e Instituto Camón Aznar 68 (1997): 156, nota 36. Es posible, pues, que esta renta de la marca derivara de la vigilancia y denuncias realizadas por el Marcador Mayor y sus Tenientes en las visitas giradas a las diversas Casas de Moneda en España. 
ducados, vale más de 10.000. Esta casa tenía intento Su Magd. que está en gloria que sirviese, después de acabada esta obra, para casa de moneda, por ilustrar esta Villa, aunque se temía contradicción de la de Toledo ${ }^{37}$.

Pompeo puede desembarazar desde luego esta casa, pues ya no tiene que hacer en ella. Y al Marcador darle casa de aposento para ejercer su oficio. Y el uno y el otro dejar la casa libre para venderla, y con el precio de ella y de los pertrechos cumplir con esta obra.

El doctor Montufar y otros fiadores de Joan Bartoli, maestro de labrar brocados y telas, a quien Su Magd. mandó prestar 4.500 ducados por 3 años, deben para el fin del que viene esta suma, de que hay escrituras de obligación a favor de Su Magd.

Julio de Junta debe 1.500 ducados que Su Magd. le mandó prestar para imprimir las obras de San Isidoro, las cuales están ya impresas, y hay obligación suya devolverlos. Son todos 6.000 ducados, los cuales se podrían consignar para estas obras, y despachar cédula para que el Pagador de ellas los cobre, y entregarle las obligaciones originales. Y con ellos y lo que procediere de la marca, entretanto que la casa y pertrechos se venden, dar prisa para que esta obra se acabe, pues no solo se crece gasto, sino que se viene aventajar más del que en ella se puede hacer.

Y se cumple con acabar una obra tan insigne como ésta y dejarla en perfección, y con la voluntad de Su Magd. que está

\section{Folio 333v:}

en gloria, demás de ser ya casa y obra de Su Magd. En Madrid, 16 de noviembre, 1599.

${ }^{37}$ Es el antiguo taller y casa del escultor y lapidario Jácome de Trezzo en el que, una vez fallecido en 1589, y comprado por Felipe II, es habilitado como obrador para Pompeo Leoni pero, también al parecer, como residencia del Marcador Mayor. Al respecto, hacia 1591 Felipe II trató de instalar en Madrid una Casa de la Moneda, precisamente en dicha casa, pero la definitiva ceca madrileña no resultaría definitiva hasta 1614. Mario Sánchez Cachero, "Las Casas de la Moneda de Madrid", La Gatera de la Villa 22 (2016): 15-20. 

CARTA DE DON JUAN DE BORJA AL DUQUE DE LERMA. MADRID. 4
DE MARZO DE $1600^{38}$

\author{
Folio 334:
}

\title{
DON JUAN DE BORJA
}

Por la consulta que con ésta va, verá Vuestra Excelencia cómo cumpliendo lo que se me mandó, visité la casa de Jácome de Trezzo. Y lo que parece que se debe ordenar, y para que esto haya efecto, me parece que será muy conveniente al servicio de $\mathrm{Su}$ Magd. que pareciendo a Su Madg. Que está bien proveído lo que digo en la consulta, se remita al marqués de Poza ${ }^{39}$ para que, vista en la Junta de Obras y Bosques, se mande ejecutar lo que se consulta a Su Magd. Guarde Dios a Vuestra Excelencia como deseo y he menester. De Madrid, 4 de marzo, 1600.

\section{AL MARGEN. EL DUQUE DE LERMA}

Para lo que digo a Vuestra Señoría en el papel que será con éste, verá lo que Su Magd. me mandó responder a Vuestra Señoría.

Volvíme aquí ayer, y con el buen tiempo que comienza a hacer se abreviará la purguilla que desean dar a Su Magd. La Divina guarde a Vuestra Señoría como yo deseo y he menester. En Toledo, a 11 de marzo, 1600.

\section{CARTA DE DON JUAN DE BORJA AL DUQUE DE LERMA. MADRID. 3 DE MARZO DE $1600^{40}$}

Folio 330:

\section{DON JUAN DE BORJA:}

El papel de Vuestra Excelencia con el que con él venía del estado de las figuras de los entierros de San Lorenzo y de la obra que se hace en la casa y obrador de Jácome, me dio Antonio Voto. Y el día del Ángel de la Guarda fuimos él y yo a verla, que tenía

\footnotetext{
${ }^{38}$ BL, Add. Ms. 28422, folio 334. Si bien esta carta es un día posterior a la última de este Apéndice, parece acompañar, en forma de nota breve, a la del día 3 de marzo, siendo ambas, la del 3 y la del 4 de marzo, respondidas por Lerma el día 11 del mismo mes y año.

${ }^{39}$ Francisco de Rojas, marqués de Poza, había sido nombrado Presidente del Consejo de Hacienda en julio de 1595, cargo que ostentó hasta enero de 1602. Con la llegada de Felipe III, en 1599 fue creada una nueva Junta de Obras y Bosques con origen en una Junta de Hacienda en la que participaron, en principio, el marqués de Poza y, entre otros, el secretario Juan de Ibarra, que provenía de la antigua Junta de época de Felipe II. A la nueva Junta de Obras y Bosques, se añadirán pronto don Juan de Borja y fray Gaspar de Córdoba, confesor real. Francisco Javier Díaz González, La Real Junta de Obras y Bosques en la época de los Austrias (Madrid: Dykinson, 2002), 133-134.

${ }^{40}$ BL, Add. Ms. 28422, folios 330, 330v, 331 y 331v.
} 
harta necesidad de ser visitada, porque no se hace nada en ella. Y juntos todos los maestros que la tienen a cargo, se trató lo que era necesario hacer en ella para que la obra se acabe por estar muy adelante, y se dé asiento en las cosas de aquella casa. Y pareció convenir lo siguiente:

Que Joan Pablo y Jácome de Trezzo acaben las piedras de la capa de la figura de la reina doña Isabel en todo este mes de marzo para que se pueda dorar la figura, y que se dé a cada uno doscientos ducados a buena cuenta.

Que Milán y Baltasar acaben de reparar el rostro y manos y la espada y tiros de la figura del príncipe don Carlos, y lo que falta de la figura y capa de la reina doña Isabel por todo este mes, y que se les dé cincuenta ducados a cada uno a buena cuenta. Y Benavides se encarga de pagar a los oficiales que les han ayudado a reparar lo que se les deben ${ }^{41}$.

Que Gasto ajuste las piedras de la capa de la figura del rey, Nuestro Señor que está en Gloria, y acabe todo lo que está a su cargo por todo este mes, y que se le den cien ducados a buena cuenta, cincuenta luego y cincuenta en fin de él.

Que Martín Pardo comience luego a dorar las figuras del rey y reina doña Ana y princesa doña María de Portugal y el sitial, que está a punto para dorar. Y pues para cuando se acaben estarán acabadas de reparar las que faltan, las comience luego a dorar, y que se le den para ello cuatrocientos ducados a buena cuenta.

\section{AL MARGEN. EL DUQUE DE LERMA:}

Su Magd. ha visto todo esto, y agradece a Vuestra Señoría el cuidado que puso en esta visita. Y todo lo que Vuestra Señoría dice y advierte aprueba Su Magd., y remite a Vuestra Señoría la ejecución de todo, y deja a su voluntad el dar cuenta de lo que le pareciere que fuere necesario al marqués de Poza y Junta de [tachado: bosques] Obras y Bosques. Dios guarde a Vuestra Excelencia como deseo. En Toledo, a 11 de marzo, 1600.

\section{Folio 330v:}

\section{DON JUAN DE BORJA:}

Y el gasto ordinario de los peones, que es poca cosa, lo vaya pagando Benavides de lo de la marca.

${ }^{41}$ Felipe de Benavides era, en época de Felipe II, Aposentador Mayor de Palacio y Tapicero Mayor

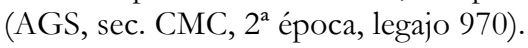


Todas estas figuras que son del rey Nuestro Señor, reina doña Ana, el sitial, princesa doña María, príncipe don Carlos, reina doña Isabel, ofrece Martín Pardo que dará doradas por todo junio, y parece que podrán estar en San Lorenzo y asentadas en su lugar para la fiesta de San Lorenzo ${ }^{42}$.

Para cuando las figuras estén acabadas de dorar, estarán acabadas de hacer las cabezas para relicarios y frontal, y se podrán dorar luego.

Están acabados y dorados los marcos de bronce de las genealogías que se han de disponer en la Sacristía, y pintadas las genealogías, y podríanse enviar a San Lorenzo para ponerse en su lugar cuando Su Magd. mandare ${ }^{43}$.

Los cogollos y coronas hace Esteban de Pedrera. Acabarán con lo que falta para fin de agosto. Podríansele dar cien ducados a buena cuenta. Y a Ribas, para vaciar los troncos de las dichas genealogías, cincuenta ducados ${ }^{44}$.

Para dorar las figuras y cabezas hay oro. La escobilla quedará recogida del dorado de las figuras de la parte del emperador y se recogerá de lo que ahora se dorare. Y de lo que saliere de ella y del que quedare del dicho dorado, se podrán dorar los cogollos y coronas proveyendo lo que faltare, que será poco.

De manera que todo el dinero que es menester proveer de presente para que esta obra se acabe monta mil y ciento y cincuenta ducados. Antonio Voto escribe a Vuestra Excelencia dónde se podrán proveer, porque de la marca no los hay del presente; y si se hubiese de esperar a proveerlo de aquello, se pasará el tiempo del dorar, que el mejor de todo el año es en el mes de marzo y abril, y se seguirá más daño de lo que importa esta suma si se pasase.

Que se haga inventario del bronce, estaño, cera, madera, jaspes, maromas, roldones, vasos, cobre, latón y todos los demás pertrechos que hay en esta ...

\section{Folio 331:}

casa. Y lo que de ello fuere menester para la obra, se dé por cuenta y razón. Y que Antonio Voto asista a él con un escribano, y tenga la llave de ello.

\footnotetext{
${ }^{42}$ No lo fueron, sino en octubre del mismo año de 1600. MULCAHY, ob. cit., p. 210.

43 Probablemente se refieran estos marcos a los de los cuadros de las cuatro Genealogías de los abuelos del emperador y el rey atribuidos a Fabrizio Castello. Al respecto indica Pérez de Tudela, «I quadri di Fabrizio Castello con le genealogie furono pertanto trasferiti in sagrestia ad inizio Seicento». Pérez de Tudela, "Marmi", 152 y p. 158, nota 123. Pantoja de la Cruz completó esta serie con las pinturas de los cenotafios y los retratos de Carlos V y Felipe II, realizados en 1599.

${ }^{44}$ Pérez de Tudela, "El cenotafio", 147-148, nota 84.
} 
Que Pompeo no tiene qué hacer desde antes que el rey Nuestro Señor falleciese. Tiene un gran cuarto de aquella casa embarazado con trastes suyos, sin posar en él él ni criado suyo. Podrásele ordenar que le desembarace luego para que se recojan en él los pertrechos y lo que fuese necesario de la obra.

Queda después de acabada la obra la casa, que es un gran sitio, con noria, pozo y jardín que, vendida con exención, valdrá más de diez mil ducados; la cual, con los dichos pertrechos, se podría vender. Y del precio de ella y de lo que procediere de la marca, averiguadas y fenecidas cuentas con todos los oficiales, había para pagarles lo que se les debiere.

Y hasta tanto esto se haga, Su Magd. ha de ser servido de mandar que en lo que va procediendo de la marca no se libre cosa ninguna, pues está consignado para este efecto. Y se cumplirá con ello hasta que esta obra se acabe y se dé asiento a las cosas de aquella casa.

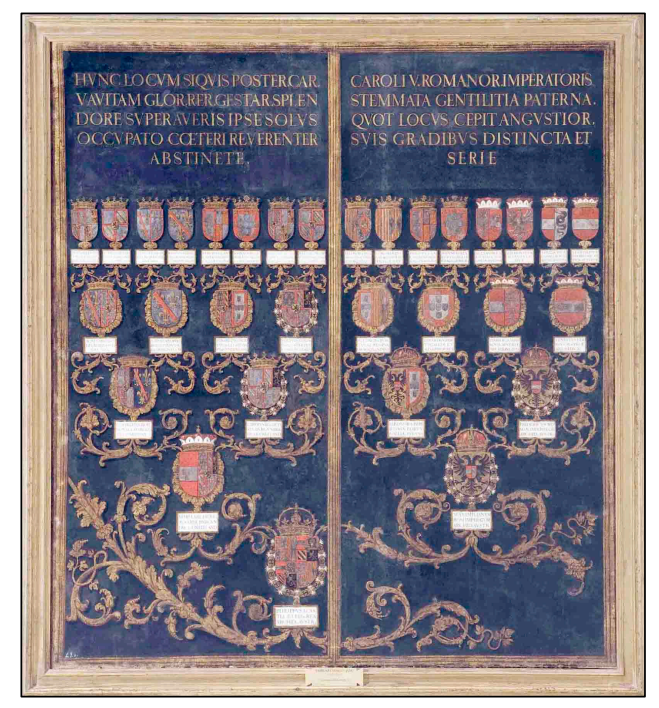

Fig. 7. Atrib. a Fabrizio Castello, Genealogía de Felipe el hermoso, Real Monasterio de El Escorial, Patrimonio Nacional. 


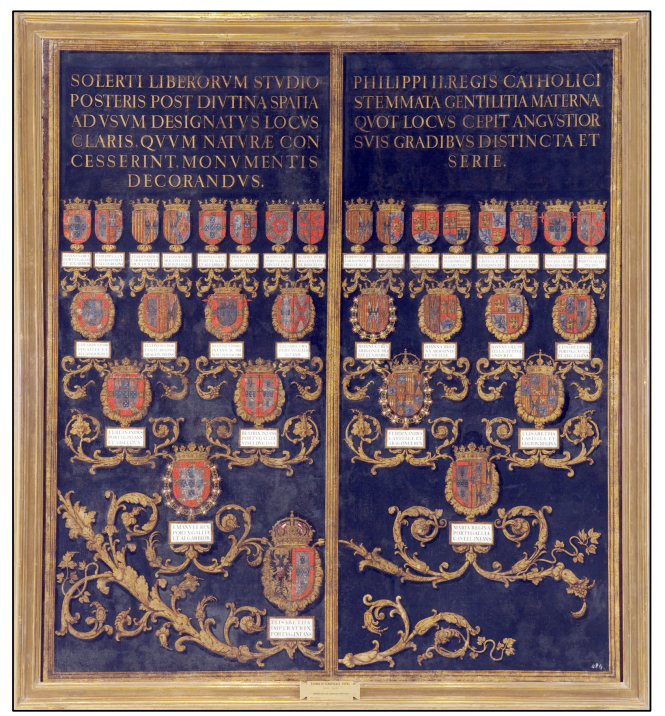

Fig. 8. Atrib. a Fabrizio Castello, Genealogía de Carlos V, Real Monasterio de El Escorial, Patrimonio Nacional.

Que se tendrá cuenta de ir visitando de ordinario esta obra, para que las figuras puedan estar puestas para la fiesta de San Lorenzo; y se haga en todo lo que conviene.

Todavía parece que faltará algún oro para el dorado de los cogollos. Y porque no se hallara cuando fuere menester, convendrá que de lo que se debe de la marca se provea algún dinero para que se compre luego de lo que ha venido en esta flota.

Pompeo no ha dado cuenta del dinero que recibió para las figuras que se hicieron en Milán para el Retablo. Podrásele pedir acabadas de asentar estas de los Entierros en su lugar.

En Madrid, tres de marzo, 1600.

Folio 331v:

Del 


\section{REFERENCIAS BIBLIOGRÁFICAS}

Jean Babelon, Jacopo da Trezzo et la construction de l'Escurial. Essai sur les arts à la cour de Philippe II, 1519-1589 (Bordeaux-Paris: Feret, 1922).

Agustín Bustamante García, "Las estatuas de bronce del Escorial. Datos para su historia (I)", Anuario del Departamento de Historia y Teoría del Arte 5 (1993): 41 57.

Agustín Bustamante García, "Las estatuas de bronce del Escorial. Datos para su historia (IV)", Anuario del Departamento de Historia y Teoría del Arte 9-10 (19971998): 153-168.

Agustín Bustamante García, "El grupo sepulcral de Felipe II", en Leone \& Pompeo Leoni, ed. Stephan F. Schröder (Madrid: Museo Nacional del Prado, 2012), 149-159.

José Luis Cano de Gardoqui García, "Noticias sobre el escultor italiano Milán de Vimercado", Boletin del Seminario de Estudios de Arte y Arqueología 54 (1988): 383-392.

José Luis Cano de Gardoqui García, "Datos para la escultura cortesana del último tercio del siglo XVI. Aspectos socio-económicos", Boletín del Seminario de Estudios de Arte y Arqueología 56 (1990): 470-478.

José Luis Cano de Gardoqui García, "COMANE, Juan Bautista", en Allgemeines Künstlerlexikon (München-Leipzig: K.G. Saur, 1998), vol. 20, 423.

José Luis Cano de Gardoqui García, "El taller de Pompeo Leoni en Milán y la obra de bronce para el retablo mayor y la custodia del Monasterio de El Escorial. Nuevos datos para su estudio", en El modelo italiano en las artes plásticas de la Peninsula Ibérica durante el Renacimiento, coord. María José Redondo Cantera, (Valladolid: Universidad de Valladolid, 2004), 455-472.

Francisco Javier Díaz González, La Real Junta de Obras y Bosques en la época de los Austrias (Madrid: Dykinson, 2002).

Antonio Feros, El Duque de Lerma. Realeza y privanza en la España de Felipe III (Madrid: Marcial Pons, 2002).

Bernardo José García García, "Los marqueses de Denia en la Corte de Felipe II: Linaje, servicio y virtud", en Felipe II (1527-1598): Europa y la monarquía católica, 2, dir. José Martínez Millán (Madrid: Parteluz, 1998), 305-332. 
Pascual de Gayangos, Catalogue of the Manuscripts in the Spanish Language in the Bristish Museum, 4 vols. (London: The Trustees of the British Museum, 1875-1883).

Francisco A. Martín, "Relicarios y piezas de altar en la basílica del Monasterio de El Escorial", Reales Sitios 82 (1984): 29-36.

Rosemarie Mulcahy, A la mayor gloria de Dios y el Rey: La decoración de la Real Basílica del Monasterio de El Escorial (Madrid: Patrimonio Nacional, 1992).

Almudena Pérez de Tudela, "El cenotafio de Carlos V en la basílica del Escorial", en Leone \& Pompeo Leoni, ed. Stephan F. Schröder (Madrid: Museo Nacional del Prado, 2012), 132-148.

Almudena Pérez de Tudela, "Marmi e pietre dure nella decozazione della basilica dell'Escorial sotto Filippo II", en Splendor Marmoris. I colori del marmo tra Roma e L'Europa, da Paolo III a Napoleone III, ed. Grégoire Extermann y Ariana Varela Braga (Roma: De Luca Editori, 2016), 139-158.

Eugène Plon, Les mâitres italiens au service de la maison d'Autriche. Leone Leoni, sculpteur de Charles V et Pompeo Leoni, sculpteur de Philippe II (Paris: Librairie Plon, 1887).

María José Redondo Cantera, El sepulcro en España en el siglo XVI. Tipología e Iconografía, (Madrid: Centro Nacional de Información y Documentación del Patrimonio Histórico, 1987).

María del Mar Royo Martínez, "Datos documentales sobre plateros y ensayadores en la Ceca de Cuenca en el siglo XVI", Boletín del Museo e Instituto Camón Aznar 68 (1997): 143-166.

Mario Sánchez Cachero, "Las Casas de la Moneda de Madrid", La Gatera de la Villa 22 (2016): 15-20.

Julián Zarco Cuevas, Documentos para la Historia del Monasterio de San Lorenzo el Real de El Escorial. IV. Historia de varios sucesos y de las cosas notables que han acaecido en España y en otras naciones desde el año de 1584 hasta el de 1603. Escrita por el P. fray Jerónimo de Sepúlveda, el Tuerto, monje jerónimo de San Lorenzo el Real de El Escorial, (Madrid: Imprenta Helénica, 1924).

Recibido: 4 de septiembre 2018 Aprobado: 23 de noviembre de 2018 